\title{
Sobre o compromisso do antropólogo e seu papel de mediador cultural
}

\author{
Alexandra Barbosa da Silva*
}

\begin{abstract}
Resumo: Seguindo a linha de uma análise crítica sobre os fundamentos do fazer antropológico, ou seja, da concepção da disciplina, do modb como lidar com seu dbjeto e dos métodos adbtados para tal, no presente texto coloco em discussão o lugar-comm, estabelecido ao longo do tempo, segundo o qual os antropólogos têm um compromisso para com os grupos com os quais trabalha. Para isto, lanço mão fundamentalmente do caso dos Guarani do estado de Mato Grosso do Sul, onde os intensos conflitos fundiários entre estes e não-índios impelem o antropólogo a ser mais do que meramente um pesquisador, portando-se como um mediador, nos vários sentidos que as demandas se lhe impõem, até mesmo sob pena de ver fracassados seus projetos de pesquisa.
\end{abstract}

Palavras-chave: antropologia crítica, compromisso do antropólogo, mediação cultural, indios Garani.

O compromisso como elemento constituinte da pesquisa

Um dos temas que a antropologia vem abordando nas últimas décadas éa análise crítica da própria disciplina, o que, juntamente com uma historiografia da antropologia (delineada por A . K uper e Stocking J r., entre outros), acabou por ser relevante para um trabalho de pensar as próprias bases, aventando-se uma reformulação em termos de concepção da disciplina, do modo como lidar com seu objeto e dos métodos adotados para tal.

A partir dos anos de 1960 e sobretudo de 1970, toda uma linha de análises constituiu o que se passou a considerar o "pós-modernismo" no campo da antropologia, em que o posicionamento do antropólogo e os contextos em que este

\footnotetext{
* Doutoranda do Programa de Pós-Graduação em A ntropologia Social do M useu Nacional / UFRJ e pesquisadora do Laboratório de Pesquisas em Etnicidade, Cultura e Desenvolvimento (Laced) / MN/UFRJ. M estre pelo mesmo programa.E-mail: ale.barbosa@ig.com.br.
}

desenvolve suas pesquisas despontam como focos privilegiados de atenção. Foi desse modo que a discussão do contexto colonial, no qual essa ciência encontrou seu pleno desenvolvimento como uma prática institucionalizada, com uma distinção profissional, tornou-se o ponto de partida para se considerar as relações entre antropologia e colonialismo, assim como os corolários dessas relações, por exemplo, a interação entre pesquisadores (provenientes de grupos dominantes) e grupos colonizados e dominados, e entre pesquisadores e governos colonialistas, trazendo à baila uma discussão sobre a cumplicidade ou não existente entre estes (a esse respeito, vide, entre outros, A sad, 1973, 1991; James, 1973; Fabian, 1983, 1991; Pels \& Salemink, 1999).

Dado que esses textos são complexos em suas discussões, a fim de que o leitor possa orientar-se, faço aqui referência a algumas das observações dos autores, apenas a título ilustrativo. Inicio, então, tomando uma afirmação de Talal A sad, que me parece sintetizar perfei- 
tamente o cerne do que intento referir. Diz esse autor:

Os antropólogos podem reivindicar ter contribuído para a herança cultural das sociedades que el es estudam por [terem feito] um registro simpático das formas de vida indígenas, as quais de outro modo estariam perdidas para a posteridade. M as, por outro lado, ocorre que eles também contribuíram, às vezes indiretamente, para a manutenção da estrutura de poder representada pelo sistema colonial. Que tais contribuições não foram, por fim, consideradas como cruciais para o vasto império que recebeu conhecimento e forneceu patrocínio, não significa que isto não foi um ponto crítico para a pequena disciplina que ofereceu conhecimento e recebeu patrocínio, pois a estrutura de poder certamente afetou a escolha teórica e o tratamento daquilo que a antropologia social objetificou - em algumas questões mais que em outras. (A sad, 1973, p 17; trad. própria)

É em continuidade a essa discussão que se coloca a análise feita por J ames (1973), sobre os contextos coloniais no qual desenvolviam suas atividades antropólogos como $M$ alinowski, Evans Pritchard e Firth, centrando-se nas condicionantes que Ihes eram impostas pela ação dos agentes coloniais. Em razão, observa J ames, da impossibilidade de apresentação de uma postura de convicção política ou obrigação moral, o que se destacou por parte dos antropólogos foi a postura de um cientificismo/objetivismo como estratégia diante desses outros agentes, e de crítica ao etnocentrismo dos missionários, administradores e oficiais dos governos e também de crítica moral às teorias evolutivas e raciais.

U ma análise de Fabian, um pouco posterior (1983), estabelece seu rumo com base na observação de que, ao longo de sua démarche histórica de produção de conhecimento, passando pelas correntes do evolucionismo, do culturalismo e do estrutural ismo, a antropologia foi uma produtora de distância temporal na construção do Outro. Colocá-lo em termos de primitivo implica, entre outras coisas, o estabelecimento de patamares temporais diversos entre o observador e os observados, negandose, desse modo, ao Outro o caráter daquilo que 0 autor considerou a coevidade, isto é, o compartilhamento de um mesmo Tempo. 0 desdobra- mento desse raciocínio, de grande alcance metodológico, além de moral, é a constatação da impossibilidade de intersubjetividade (ou seja, a anulação de distanciamento) que toda interação social pressupõe, constituindo o que Fabian denominou não de um anacronismo, mas propriamente o expediente (existencial, retórico, político) do alocronismo da antropologia.

Já Pels \& Salemink trazem uma interessante discussão sobre a autoridade do antropólogo, tendo como ponto de partida a idéia de que o lugar de produção de conhecimento antropológico por excelência é a academia. Eles observam que, na verdade, a produção de concei tos tornados centrais para a disciplina nem sempre se deu na academia, mas a partir das viagens realizadas por comerciantes (cf. 1999). I mporta-me aqui, sobretudo, destacar a atenção dada pelos autores à percepção da etnografia como um processo prático e não como um texto ou um método ideal, para isto sistematizando uma divisão analítica do processo etnográfico em três fases, a saber, o pré-campo, a "ocasião etnográfica" e a "tradição etnográfica" (Pels $\&$ Salemink, p. 12). 0 pré-campo é uma noção tomada a . Clifford (o préterrain), ${ }^{1}$ implicando este todas as relações e lugares que precondicionam o trabal ho da etnografia, ou seja,

as relações espaço-temporais híbridas: práticas mercantis, coloniais ou discursivas acadêmicas, que definem a possibilidade e a necessidade de ir ' para lá'; meios de transporte e formas de residência; relações de poder com e dentro das sociedades que o etnógrafo irá descrever, e os modos de produção e reprodução dessas relações. (Pels \& Salemink, p. 13)

A "ocasião etnográfica", poder-se-ia dizer, é, no jargão antropológico, o "campo" propriamente dito, o qual os autores definem em termos da "situação de contato entre o etnógrafo e aqueles a serem descritos" (Pels \& Salemink). Por fim, a "tradição etnográfica" são os textos que compõem o acervo da disciplina, os quais, observam Pels \& Salemink, "tendem a obscurecer o que os contextualiza". A demais, para eles,

1. No texto "Traveling Cultures", in L. Grossberg, C. Nelson e P. Teichler (eds.), Cultural Studies. New York and London: Routledge. 1992. 
É crucial ver uma tradição etnográfica ela própria como um processo prático, de modo a ver em que medida uma continuidade do précampo, da ocasião etnográfica e da tradição etnográfica persistiu, ou se mudanças maiores no pré-campo ena ocasião etnográfica alteraram o significado dos temas recorrentes ou dos lugares-comuns que marcam a tradição. (Pels $\&$ Salemink, p. 14)

Pois bem, em continuidade com essa linha de análise crítica, penso que um dos pontos a merecer reflexão é uma questão para muitos tida como despropositada, que é a do porquê, para que e, sobretudo, para quem se praticar antropologia atual mente. Concomitanteé, a meu ver, a necessidade de se questionar o lugarcomum, que se estabeleceu ao longo do tempo, de que os antropólogos têm um compromisso com os grupos com os quais trabal ham.

A o se lidar com a idéia de que é próprio da antropologia como ciência anal isar as lógicas de entendimento do mundo de povos étnica, social e cul tural mente diferenciados, contribuindo-se, desse modo, para mel horar o diálogo entre eles, é de se observar, antes de mais nada, que isto compreende um processo que envolve uma multiplicidade de autores no campo ${ }^{2}$ acadêmico e de agentes externos a este, todos os quais dispõem de concepções particulares. E se esse processo acaba por resultar em um efeito de propagação da informação da academia em direção ao senso comum, isso ocorre de modo absurdamente lento e não-homogêneo, com apropriações variadas e muitas distorções. Em suma, trata-se de um processo que é fundamentalmente político e, como tal, há sempre os beneficiados e os não-beneficiados pelos seus resultados.

2. Utilizo aqui a categoria "campo" com base em todo um conjunto de análises de P. Bourdieu, que tem por objeto conformar uma teoria dos campos - científico, literário, econômico etc. Para esse autor, num espaço mais ou menos conformado (um campo), os agentes são portadores de capitais (capital cultural, capital social etc.), observando ele que, segundo as suas trajetórias, esses agentes têm uma propensão a orientarem-se num duplo sentido: ou o da ortodoxia, quer dizer, o da conservação do estado de coisas - caso daqueles que encontram-se já estabelecidos, consagrados -, ou 0 da heresia, quer dizer, o da sua subversão. A título de ilustração de ordem empírica dessa proposta, ver Bourdieu, 1994 e 1996.
É de se lembrar, também, que o referido lugar-comum pode nem mesmo ser cogitado. De fato, muitas vezes o sentido de se praticar a antropologia não está senão na mera reprodução do jogo de prestígio e títulos do campo acadêmico.

No sentido propriamente "objetivo" do trabalho científico, detenhamo-nos por um momento sobre o cânone da neutralidade axiológica, que constituiu a antropologia como uma pretendida ciência. Vemos, então, que N orbert Elias, hoje autor reconhecido no âmbito das ciências sociais, é um dos seus mais notáveis defensores. No livro intitulado Engagement et distanciation, 0 autor tece uma análise sobre os problemas com os quais se defronta o cientista em geral. Parte ele de uma percepção (positivista) de que um controle das emoções ter-se-ia operado ao longo do tempo no progresso da ciência (o que por si implica uma visão de ciência como cumulativa), algo que haveria permitido maior objetividade do cientista nas suas análises. Essa visão da objetividade - e, portanto, de uma neutralidade - tem suas raízes no seguinte raciocínio:

Como os outros homens, os cientistas se deixam guiar em seu trabalho, em uma certa medida, por desejos e inclinações pessoais. Eles são muito freqüentemente influenciados pelos interesses de grupos aos quais pertencem. Eles podem ter em vista uma promoção em suas carreiras, podem esperar que os resultados de suas pesquisas estejam de acordo com as teorias que el es sustentaram ou com as exigências e os ideais dos grupos com os quais se identificam. (Elias, 1993, p. 12-13; trad. própria)

Elias concebe como "tendências ao engajamento" do cientista uma falta de controle dos seus afetos, diante dos quais deve necessariamente estabelecer um "distanciamento". Reportando-se mais especificamente ao cientista social, para quem esse problema se apresentaria de modo muito mais incisivo do que para o cientista "da natureza", o autor diz que

Entre os pesquisadores em ciências sociais não faltam as tentativas para se distanciar de uma posição de testemunha engajada nos fenô- 
menos sociais e para se liberar da perspectiva limitada que este papel implica. (Elias, 1993, p. 24).

A testando-se que esse cânone da neutralidade permanece bastante presente como orientação e premissa, o que temos, na verdade, é um debate constitutivo das disciplinas (a antropologia inclusive), aquele da pura objetividade científica versus o compromisso ético e político com o grupo pesquisado.

Tomo, então, como ponto de partida para discussão a questão se os sentidos que esse lugar-comum pode ter devem ser eles próprios objeto de questionamento. E m outras palavras, a pergunta que me conduzirá e que permeará este texto daqui em diante é: quais as formas que esse compromisso pode assumir?

U ma das concretizações que essa discussão encontrou foi o debate estabelecido em al guns países da $A$ mérica $L$ atina, fundamentado no confronto entre uma concepção de ciência "aplicada" ou "prática", estabelecida em oposição a uma pensada como "pura". Para ser mais precisa, essa discussão teve lugar em países como M éxico, Peru, Bolívia, locais onde se estabeleceu uma aproximação entre antropologia e indigenismo, estando em jogo a avaliação dos "projetos de desenvolvimento social" a serem aplicados aos grupos nativos, com o intuito de sanar problemas de ordem prática. ${ }^{3}$

Resta destacar o quão equivocada é essa dicotomização, pelo velho princípio dialético da relação entre teoria e práxis, ou seja, pela consideração de que toda teoria, sendo gerada pela prática, tem ela própria um efeito prático, e que uma experiência de atuação prática pode em muito contribuir para o enriquecimento do corpus teórico da disciplina. É também disto que trata uma proposta de refletir sobre os fundamentos da antropologia.

Pois bem, al go que não constitui novidade alguma nas reflexões antropológicas é que, como membro das classes dominantes (vista a origem da imensa maioria dos antropólogos, fato que no Brasil se mostra de modo bastante evidente) e como al guém que domina códigos e

3. Sobre a relação entre antropologia e indigenismo, ver, entre outros, Rojas, 1971, e Lima, 1995. expressa habilidades próprias da sociedade dominante, o antropólogo é encarado pelos indivíduos e grupos com quem lida como al guém que pode ser útil na concretização de determinados interesses seus. Isto pode se expressar desde a mera solicitação de dinhei ro ou objetos às mais diversas demandas. Obviamente que a negociação dos termos dessa troca é regida pelas reais condições de que 0 antropólogo dispõe. I sto posto, temos aberta a questão: dada a complexidade dos elementos em jogo na interação pesquisador (antropólogo)-grupo pesquisado, quais devem ser as bases da troca que necessariamente se estabelece, nessa interação, entre essas partes?

Em resposta, apresento inicial mente al guns postulados que, no meu entender, devem ser diretrizes da postura ética de um antropólogo. Seguindo a linha dos autores-críticos arrolados neste texto, entendo que a pretensão de uma antropologia como um estudo politicamente desinteressado de "outras culturas" ou grupos sociais implica uma quimera que encobre as condicionantes políticas, sociais, culturais e econômicas de toda pesquisa (e não só as da área "social", mas também as da área "da natureza" ou "exatas"), e que relega as condições de desigualdade também política, social, cultural e econômica reinantes nas situações de dominação não só sobre os povos indígenas, mas também sobre as chamadas "classes trabal hadoras", "favelados", "trabalhadores rurais", enfim, todas as categorias utilizadas para qualificar as partes dominadas no jogo das relações sociais entendidas de modo amplo. Penso que, antes de retomar e reificar uma discussão da separação entre ciência e política, teoria e prática, o que é ef etivamente rel evante é ter uma postura na convivência no cotidiano da pesquisa, de estabelecer um compromisso político com os interesses apresentados pelos indivíduos e grupos com os quais se trabalha. Entendo também que ter como premissa que a pesquisa se constituirá como uma interação, sendo premente um espaço para a manifestação do "Outro" como ser dotado de interesses próprios, interesses que, por sua vez, serão confrontados com os do pesquisador, é uma postura metodológica que traduz uma intenção 
de reciprocidade e abre caminho para uma relação de maior equilíbrio entre essas partes. ${ }^{4}$ 0 nó da questão parece-me estar na capacidade de o pesquisador dar-se conta do que está sendo dele esperado, ou seja, da sua disposição para ter essa percepção e, a partir disto, dialogar abertamente com seus interlocutores.

$\mathrm{N}$ esse sentido, a pesquisa, como a concebo, parte do princípio de que o grupo e suas condições de vida devem constituir o ponto de partida da investigação, e que um esforço, por parte do antropólogo, de aproximação dos problemas e interesses de seus pesquisados é uma necessidade que se põe em qualquer situação de pesquisa (e cuja percepção é fundamental, sob pena de ser criado um hiato intransponível e esterilizante de comunicação, com prejuízos até mesmo fatais para a pesquisa). Essa aproximação, eu a definiria em termos de um entendimento, ${ }^{5}$ em que o pesquisador dispõese explicitamente a buscar os meios para atender a esses problemas e interesses, sendo esse esforço, el e mesmo, constitutivo da interação que a pesquisa representa. Expresso nesses termos, esse "entendimento" é bem diverso de um "compromisso" assumido como um apêndice da pesquisa. N esse último caso, a objetividade

4. Nessa direção, tenho como orientação as reflexões de Pels \& Salemink (1999), remetendo-me à noção de "ocasião etnográfica" aqui já referida. 0 que me importa ressaltar é que os autores pensam em termos de uma situação de interação - e, nesse ponto, Fabian (1991) refletiria mais em termos de um confronto -, com todo um background, digamos assim, que cada parte dessa interação traz consigo. Ressalvo, no entanto, que retomo-Ihes a intenção que dá origem à noção, mas considerando-a restritiva, por preferir antes pensar em termos de uma "situação etnográfica", uma vez que esta deixa mais clara uma idéia de contexto.

5. Nesse ponto, parece-me interessante abrir um parêntese e fazer referência a um termo utilizado pelos Guarani contemporâneos, pela sua possível valia nesta discussão. Trata-se do termo oñontendê, o qual me foi referido para explicar como se dá a união entre duas pessoas - ou seja, o que chamaríamos casamento ou matrimônio. Para se unir, duas pessoas precisam oñontendê (ao que parece, uma adaptação do português "entender", já que, em "guarani original", um termo utilizado para "entender" é "oiko"); é o entendimento que permite que um casal siga junto numa relação; quando deixa de entender-se (ou seja, noñontendê), a relação acaba desfazendo-se, o que tem ocorrido com uma freqüência bastante alta entre esses índios, estabelecendo-se então novas relações, sempre com 0 intuito de conseguir 0 entendimento. 0 termo pode também ser utilizado para as relações entre pais e filhos e entre parentes e aliados em geral. Desse modo, a compreensão entre duas partes é um valor de extrema relevância, cultivado com zelo pelas pessoas. científica estabelece-se como orientação apriorística para o pesquisador, e um compromisso político pode dar-se num espaço e num momento externos à pesquisa. Desse modo, 0 pesquisador pode até militar em al guma instância (ONG , sindicato, o que seja), mas a pesquisa é essencial mente um momento de busca dos dados que lhe interessam.

0 que merece questionamento, contudo, nesse ponto, é se o próprio fato de aliar-se politicamente, em al guma instância, aos "informantes" não é um fator preponderante para a qualidade dos dados obtidos. Defendo que a qualidade da compreensão sobre os grupos pesquisados, indubitavelmente, está diretamente relacionada ao "entendimento", conforme 0 compreendo. Ao se estabelecer no cotidiano uma aproximação dos interesses dos sujeitos, 0 nível de interação e a profundidade das informações que vêm à tona são, visto que há uma relação de compartilhamento em jogo, muito superiores ao que seria possível em caso contrário, em que se estabelece exatamente um "distanciamento". U ma conseqüência é que os sujeitos com quem nos confrontamos não se constituem meramente como "informantes", a nos transmitir a matéria-prima que buscamos para a concretização de nossa etnografia.

Deve-se ter em mente que o exercício da antropologia pode-se constituir em um mero exercício de poder se os métodos de pesquisa e os pressupostos teóricos, tidos por cânones, definidos de um ponto de vista que é externo e temporalmente antecedente ao grupo que será abordado, não forem em nada alterados quando da "ocasião etnográfica" (nesse caso, conforme a compreendem Pels \& Salemink). Tomar isto como pressuposto não equivale meramente a reproduzir as velhas lições de manuais de metodologia, da necessidade de adequação das questões formuladas às circunstâncias dadas pelo "campo". O que proponho é algo de natureza totalmente diversa.

\section{As vicissitudes do campo}

Esta introdução de caráter mais teórico sobre a relação antropologia-objeto, antropólogo- "informante" e esta proposta de condução do fazer antropológico têm raízes não 
apenas nas leituras citadas, mas também em minha própria experiência prática entre grupos Guarani, em M ato Grosso do Sul. Esta experiência, por sua vez, deu continuidade àquelas de diversos outros antropólogos, que desde os anos 1970 vêm tendo grande relevância no processo histórico das relações interétnicas envolvendo não-índios (brasileiros e paraguaios) e os Guarani, na fronteira entre o B rasil e o Paraguai.

Essa atuação dos antropólogos teve seu início de forma constante nos anos 1970, não apenas como pesquisadores, mas também com a constituição de ONGs que desenvolveram projetos de desenvolvimento - como o Projeto Paî Tavyterã (PPT) e o Projeto Kaiowa$\tilde{N}$ andéva $(P K \tilde{N}) .6$ Paral elamente, passou a atuar também na região 0 Consel ho Indigenista M issionário (Cimi), de modo que, ao longo do tempo, foi-se constituindo o que Oliveira (1988) denominou "campo de ação indigenista". 0 antropólogo acabou por ser enquadrado num conjunto de vários outros atores, incluindo proprietários rurais, a Funai, prefeitos, deputados e, mais recentemente, o M inistério Público Federal, este último sendo visto nesse "campo" na posição de aliado ou de oponente, dependendo do contexto em pauta e das partes envolvidas.

$\mathrm{N}$ esses termos, nas próximas linhas vou refletir sobre questões como a presença e o papel do pesquisador junto aos grupos com que interage, tomando como referência uma experiência do antropólogo G eorg Grünberg ea minha própria experiência de pesquisa.

Numa conferência apresentada em 1991, Grünberg (2000) narrou sua inserção numa comunidade Guarani no Paraguai ${ }^{7}$ no ano de 1971. Conta-nos ele que, juntamente com sua esposa, uma lingüista, recebeu uma muito boa

6. Mais adiante, farei breve referência ao PPT, que se efetivou no Paraguai. Já o PKÑ foi, de algum modo, um correspondente, no lado brasileiro, do PPT, e sobre suas atividades pode-se consultar Thomaz de Almeida (2001).

7. Historicamente o território ocupado pelos Guarani, em seus três subgrupos considerados pela literatura pertinente (ou seja, os Kaiowa, os Ñ andéva e os M bya), inclui, entre outras regiões, a fronteira entre a parte oriental do Paraguai - Kaiowa (denominados Paî-Tavyterã), Ñ andéva (denominados Chiripa) e M bya - e o estado de M ato Grosso do Sul (Kaiowa e Ñandéva), área a que me importa aqui fazer referência. acolhida, tendo-Ihes sido possível um razoável aprendizado da língua daquele grupo, ao adotarem uma conduta de aprendizagem e reprodução das suas atividades cotidianas. Não obstante essa boa receptividade, em determinado momento de sua estada (ou seja, três meses após a chegada), o casal G rünberg viuse encurralado por problemas que os índios the apresentaram após a realização de uma reunião interna. Esses problemas versavam em torno das questões, para o grupo, cruciais naquele momento - o que conformava uma determinada situação histórica. ${ }^{8} \mathrm{Um}$ desses problemas era como fazer para defender a terra deles contra pessoas armadas, que ali nunca haviam estado e que se diziam proprietários dela; o outro era relacionado a doenças, mormente a tuberculose, que fora introduzida pel os brancos e para a qual não dispunham de remédios, apesar do vasto conhecimento de meios curativos que acumulavam; o terceiro e último problema era a necessidade de documentos, cobrados pelos militares no lado brasileiro da fronteira, que lhes agrediam por causa da falta desses papéis. ${ }^{9}$ Complementando o discurso, disseram que, se os G rünberg pudessem ajudá-los, poderiam ficar, mas, do contrário, Ihes seria desejada boa viagem. Provavel mente seus parentes estariam esperando-os com ansiedade, uma vez que ali estavam já havia bastante tempo $(2000$, p. 63 65). Os G rünberg acabaram por aceitar a tarefa proposta e criaram o Projeto Paî-Tavyterã (PPT), o qual empreendeu esforços para a garantia de terras, das quais os índios passaram legalmente a dispor no Paraguai.

Três décadas depois da experiência dos Grünberg e, como dito, tendo vários outros antropólogos (e não só eles) estado entre os Guarani, dos dois lados da fronteira, confrontei-

8. Seguindo a definição de Oliveira (1988): “[...] uso aqui a expressão situação histórica, noção que não se refere a eventos isolados, mas a modelos ou esquemas de distribuição de poder entre diversos atores sociais" (p. 57).

9. Para esse período referido por Grünberg, não disponho no momento de dados para comparar a situação relativa à saúde dos Guarani no lado brasileiro da fronteira, nem tampouco sobre a atuação do sistema de policiamento do lado paraguaio, referente ao fluxo de pessoas naquela direção. Contudo, no que tange ao problema fundiário, a situação de expropriação das terras de ocupação histórica dos Guarani, em consequência do fomento dos governos à colonização, era comum nos dois lados da fronteira. 
me com grupos dessa etnia no sul de MS. É necessário, abrindo-se um parêntese, observar que entre $B$ rasil e Paraguai há uma diversidade tanto no que diz respeito às respectivas legislações atinentes à terra, quanto aos processos históricos de recuperação dessas terras por parte dos indígenas. No que tange ao B rasil há, podese dizer, duas fases de delimitação da terra, a primeira éa constituição de oito reservas criadas pelo então SPI entre 1915 e 1928, e a segunda, a definição de áreas (atualmente em cerca de 18, entre identificadas, demarcadas, homologadas e "em identificação") a partir da reivindicação dos próprios índios, num processo que se iniciou em fins dos anos 1970 - como se verá logo adiante. Já no que se refere ao Paraguai, particularmente aos Paî-Tavyterã, com a atuação direta do Projeto Paî-Tavyterã e por meio de um processo de negociação dos espaços delimitados, foram demarcadas 24 áreas até 0 ano de 1975. Com relação aos Chiripa, foram 14 as áreas demarcadas até 1988 (para dados neste sentido, ver M elià et alii, 1976; PPT/PG, 1977; Chase-Sardi et alii, 1990, Thomaz de A Imeida, 2001; M ura \& Thomaz de Almeida, 2002).

A situação dos K aiowa e dos Ñ andéva de MS, com quem passei a conviver no ano de 2000 , fez-me perceber que o problema da terra existe para eles com o mesmo caráter de emergência que fora posto aos Grünberg no Paraguai, não obstante as mudanças ocorridas em conseqüência do processo histórico e de termos atual mente uma nova situação histórica nas relações interétnicas no sul de M S. A partir do final dos anos 1970, esses dois subgrupos Guarani iniciaram um esforço de recuperação de seus lugares historicamente ocupados (tekoha), esforço que tem alcançado um relativo êxito, mas que se mantém fortemente ativo, sendo a demanda estimada (pois que não há dados concretos nesse sentido) atualmente na casa de algumas dezenas de tekoha.

Essas conquistas tiveram início nos anos 1980, com a identificação da "terras indígenas", e adensaram nos anos 1990, sobretudo em razão das mudanças introduzidas na Constituição de 1988, com a afirmação dos direitos indígenas sobre a terra considerada como de ocupação tradicional. Nesses termos, o antropólogo tornou-se um agente-chave como formulador dos chamados laudos de identificação e periciais de terras indígenas. Especificamente nesse ponto é de se recordar que a construção do conhecimento em antropologia - sendo um laudo antropológico também um produto dessa ordem - não se dá por uma questão de simpatias, mas de conhecimentos e técnicas adquiridos em longos tempos de formação, com uma fundamentação sobre as informações prestadas pelo grupo, as quais devem passar pelo crivo propriamente técnico de uma análise antropológica, a saber, o cotejo das informações entre diversos sujeitos, buscando-se o refinamento dessas informações. U m outro procedimento utilizado, quando necessário, é a busca de informação histórica e de documentação que possa dar respaldo a essas informações.

Deve-se ter em mente, então, que 0 fato de ser o responsável imediato por esse trabal ho técnico faz com que, para os demais atores presentes na região, o pesquisador não fique separado da figura do técnico.

A ssim, no tocante a essa questão - e de modo complementar à questão da necessidade de tomar em consideração os interesses dos grupos pesquisados - , se para os atores referidos a separação entre o técnico e o pesquisador não aparece, para o próprio antropólogo as coisas tornam-se ainda mais complexas, caso a tarefa para a qual se prontificou não seja de caráter técnico. Sendo el a de caráter acadêmico, e tendo em conta sua preparação voltada para dar conta de questões elaboradas na academia, esse quadro de conflito fundiário como pano defundo, mais que determinante nas relações interétnicas locais, apresenta-Ihe algumas complicações. Conforme pude concluir, se na chegada a uma determinada área indígena, pode até ser imediatamente acolhido por uma família indígena (em vista dos recursos que el e possa trazer, al ém da sua utilização nas disputas internas do jogo político e de prestígio entre as famílias, internamente dentro das próprias áreas indígenas), de modo geral, no nível da comunidade (com a qual ele necessariamente precisa interagir, no desenvolvimento da pesquisa), a presença do antropólogo pode tornar-se problemática, caso ela (a comunidade) se encontrar imersa em uma determinada ordem de problemas. Semel hante 
ao que ocorreu com os Grünberg, em momentos propriamente de mobilização na luta pela terra - mas não apenas nesses casos, que devem ser vistos somente como um exemplo possível, e observando-se que não necessariamente tem de estar em questão uma comunidade, mas também devem ser levadas em consideração as condições de sujeitos individuais ou de determinada família ou grupo, dependendo do universo com o qual o pesquisador esteja envolvido -, um antropólogo que se posicione como um pesquisador, com um interesse acadêmico específico, torna-se fora de lugar, supérfluo ou, quando muito, suportado (se não indesejado).

\section{M inha experiência: o antropólogo como um mediador}

Neste ponto, remeto-me novamente a minha própria experiência entre os $G$ uarani. Esta iniciou-se mais precisamente entre os K aiowa, em agosto de 2000, junto a meu companheiro, também antropólogo e que desenvolve pesquisas entre os Guarani há al guns anos, em uma área ocupada que recentemente recebera um grupo técnico (GT) da Funai para a identificação. Com uma idéia em gestação de analisar os efeitos da atuação do Estado sobre 0 assentamento de populações etnicamente diferenciadas e levando em conta os diferentes motivos, os diversos atores e as agências governamentais envolvidos, tendo como referência uma mesma situação social (Gluckman, 1987), eu tencionava investigar tanto uma situação de ocupação de terra pelo M ST, quanto uma indígena.

Portadores de uma carta de apresentação do antropólogo coordenador do referido GT, a nossa intenção de ali permanecer, a fim de melhor conhecer o modo como viviam, foi acolhida. Evidentemente, a associação estabelecida entre nós e 0 antropólogo por el es conhecido garantiu-nos de imediato essa acolhida, significando ela - como a cada dia, naquele período, tornava-se mais perceptível para nós um empenho de confiança e uma esperada reciprocidade de nossa parte.

A o longo daqueles dias, as experiências que vivemos dizem muito sobre a posição do antropólogo em M S, e eu passo a compor uma reflexão nesse sentido, com breves contextualizações.
$\mathrm{Na}$ área, os índios, em cerca de 350, entre adul tos e crianças, estavam confinados em um espaço de 24 hectares, 0 qual fora resultado de um acordo estabelecido entre eles e o prefeito (que tivera, junto com seu pai e o irmão, suas terras ocupadas e compreendidas na identificação), por um prazo que já havia há muito tempo expirado. Sabendo de nossa presença na cidade e que nos dirigíamos ao acampamento, 0 pai do prefeito mandou-nos chamar. A ele expusemos nossa intenção de desenvolver pesquisas junto aos índios e lá permanecermos inicialmente por al guns dias. A ssim, ele solicitounos que disséssemos aos índios para ficar calmos e se manterem onde estavam até que tudo se resolvesse - ou seja, que el e recebesse a indenização que Ihe era devida e se retirasse com a família. U m clima de desconfiança e certa tensão marcaram essa nossa conversa, embora 0 fazendeiro se esforçasse por mostrar-se cordial.

A pós esse episódio, estabelecemo-nos no acampamento e fomos tomando ciência da situação altamente tensa que reinava entre os índios e a família do prefeito. No correr do tempo, tivemos conhecimento da série de proibições impostas aos índios, com origem na impossibilidade de deixar o "chiqueirinho" - como estes chamavam o espaço de que dispunham. EraIhes vedado caçar, pescar, buscar sapê, e, sobretudo, cruzar a fazenda em direção à outra área indígena, situada já no Paraguai, a cerca de $7 \mathrm{~km}$ de distância, com a qual mantinham relações de parentesco e aliança. Conforme registrado na literatura, esse caminhar (oguata) pelo território é de fundamental importância na vida dos Guarani, el emento que constitui e mantém as relações tanto intra quanto intercomunitárias. Restritos a um espaço extremamente exíguo para suas características de morfologia e organização social, os índios viam-se numa situação comparável a uma panela de pressão.

Certo dia, aproveitando-se exatamente de nossa presença, 0 chefe político do grupo (o capitão) veio dizer-nos que, na manhã seguinte, um grupo iria à referida área indígena no Paraguai e convidou-nos a acompanhá-los, o que fizemos. A o saber do fato, a reação do fazendeiro foi de grande irritação e, dali por diante, nossa presença foi diversas vezes por ele solicitada para conversas. Assim, até pouco 
antes de nossa partida, vimo-nos transformados em mensageiros por ambas as partes, de modo que, se a figura do antropólogo é vista como a de um mediador, naquela situação isto se deu de modo literal. O s índios, sabendo que éramos chamados pel o fazendeiro, apresentavam-nos a demanda de poder ir além do "chiquei rinho"; 0 fazendeiro solicitava exatamente o contrário.

Essa situação estabeleceu-se em razão da impossibilidade de diálogo entre as partes. Em termos mais exatos, comunicação existia entre elas, e esta dava-se através dos incidentes que ocorriam - como uma flecha atirada em direção ao carro do filho do prefeito e a apreensão impetrada pelos índios de caminhões que retiravam madeira cortada na área já então identificada. Contudo, um diálogo direto mostrava-se impossível pela diversidade das posições e concepções em jogo. Dito de outro modo, por tudo o que comportava a diferença étnica naquele contexto social, político e econômico, implicando isto a adscrição a valores, conceitos e crenças e a um modo de se relacionar com a terra diametralmente diversos. ${ }^{10}$

Para compreender mel hor os elementos em causa, importa dizer que, num momento anterior, era possível uma relação não apenas baseada no trabalho que alguns índios presentes no acampamento prestavam havia anos a esse fazendeiro, mas também em algo a que este imputava relevância: o fato de ser padrinho desses mesmos índios. Desse modo, a seus olhos, a presença deles no grupo reivindicante aparecia-Ihe como uma traição - conforme efetivamente nos informou. No discurso desses mesmos índios, essa última relação não aparecia no horizonte dos fatos relevantes; o que surgia era o desabafo dos constrangimentos e da subjugação acumulados ao longo do tempo, fundamentados todos sobre a expropriação da terra, que então se haviam disposto a reivindicar. Como é perceptível, naquele momento a diversidade étnica tornava-se absolutamente

10. Para os Guarani, a terra (yvy) foi-Ihes dada por Ñande Ru Vusu, uma das entidades supremas de seu panteão, para que ali vivessem e para que dela cuidassem, a fim de evitar que males recaíssem sobre o local, ameaçando toda espécie de vida que nela se desenvolve. Daí, como ocorre com vários outros grupos indígenas, a concepção dos Guarani é que são eles que pertencem à terra (que é uma terra - no sentido de território - específica) e não o contrário. presente e preponderante, avivada em todos os sentidos em face do objeto em disputa.

Nesse contexto, aparecíamos como um meio de enviar mensagens à parte oposta, cada qual marcando sua posição e com uma determinada percepção da situação. N ossa constatação (dos antropólogos) era que não haveria nenhum avanço em termos de concessão, e vimos que os índios tinham essa mesma percepção. $E$, no entanto, o fazendeiro parecia esperar que tivéssemos algum êxito, por dispor de uma (suposta) autoridade perante os índios. Essa sua atitude, por um lado, era devida claramente à impossibilidade de pôr em prática a forma de comunicação historicamente utilizada pela sua categoria na região: 0 uso da força. Por outro lado, espelhava uma percepção de que os Guarani não eram os mentores do movimento de reivindicação, havendo uma versão muito arraigada entre os proprietários de terra de que as ocupações fundiárias têm sido fruto de iniciativas e ações de "brancos" (ou melhor, de agentes de ONGs nacionais e estrangeiras, do Cimi e de antropólogos), dado que, de seu ponto de vista, eles "sempre tiveram uma convivência pacífica com os índios". Certamente, para essa visão contribuiu a postura não agressiva dos Guarani (expressão de um correto, apropriado, modo de ser perante 0 mundo e as pessoas, 0 teko porã) e a evitação de conflitos abertos, 0 que os fazia figurar como um povo submisso, visão que torna essência aquilo que é resul tado de uma luta com premissas e armas desiguais, num longo processo de dominação. Por outro lado, é bem apropriado notar que a presença daqueles atores externos foi fundamental para que surgissem as condições para uma modificação no jogo de forças estabelecido. A ssim sendo, a idéia de mancomunação, com liderança da parte dos "brancos", estava firmemente arraigada no pensamento desses proprietários.

A pós essa experiência, permaneci ainda por um período em uma outra situação de reivindicação de tekoha e estive presente em três das reuniões ${ }^{11}$ que aglutinaram representantes de um grande número de tekoha de M S, nas quais os problemas e interesses de cada um

11. U ma delas numa área que estava sendo reivindicada e onde foi assassinado 0 ancião $M$ arcos Verón, então articulador dessa demanda. 
eram apresentados para os demais, constituindo esses eventos uma grande assembléia (a aty guasu, donde aty $=$ reunião e guasu $=$ grande) e a instância de representatividade de caráter mais amplo existente entre os G uarani de M S, de modo que tem sido a partir dessa inserção que venho conhecendo líderes políticos e sendo por eles conhecida, ou seja, como al guém que tem compartilhado de seus problemas. Desse modo, meu interesse em aprender sobre seu modo de viver tem sido acolhido com grande paciência, dada a disposição de determinados indivíduos para ensinar e explicar. 0 gesto de levar mantimentos para as famílias e fazer as refeições com elas é também um elemento de aproximação e que possibilita o desfrute de conversas e de convivência.

Nessa convivência, mais de uma vez foime solicitado auxílio para a elaboração de projetos para obtenção de recursos - por exemplo, de bens que atendem a necessidades de produção, tais como sementes, carroças, tratores e seus implementos. É nesse jogo de interação que venho obtendo uma ampla gama de dados, muitas vezes mesmo inesperados por sua complexidade.

Importa dizer que findei por construir meu projeto de pesquisa para doutoramento tendo por objeto a investigação dos efeitos da territorialização ${ }^{12}$ sobre o modo como os K aiowa e os Ñandéva passaram a se estabelecer no seu território de ocupação histórica. M inhas reflexões vão no sentido de investigar o modo como esses indígenas concebem e vivenciam um território, tanto como espaço cogni tivamente conhecido, quanto como local de experiências intra e interétnicas.

A observação a que tenho me dedicado dos efeitos que a socialização ef etuada tanto nas terras indígenas (TIS) constituídas, quanto nas fazendas e nas cidades de MS, têm sobre a identidade dos indivíduos e dos grupos e da construção e manutenção das redes de relações que perpassam esses locais de estabel ecimento - permite-me perceber que o fundamento exato desses estabelecimentos está em que ele se

12. Entendida esta, segundo Oliveira (1999, p. 21), como "uma intervenção da esfera política que associa - de forma prescritiva e insofismável - um conjunto de indivíduos e grupos a limites geográficos bem determinados". realiza dentro de um limite específico, sendo este o que configurava no passado (e que permanece como tal na concepção dos índios) um tekoha guasu - ou seja, um território caracterizado por relações que se desenvolvem conectando e perpassando vários tekoha, embasadas quer por parentesco, quer por aliança (casamento). Cada família nucl ear mantém, é importante destacar, como referência fundamental o tamõi (avô), e este tem por referência o tekoha ao qual pertence. A ssim, ao fim, o que temos são famílias extensas que se reconhecem pelas interações que desenvolveram e desenvolvem ao longo do tempo em um espaço específico.

0 aprofundamento desta pesquisa, ou seja, a análise com metodologias próprias à antropologia, éque possibilitará explicar mais apropriadamente, em termos científicos, os critérios que embasam as iniciativas aguerridas com que os Guarani vêm reivindicando as terras que consideram como de sua morada e existência.

\section{Conclusões}

$\mathrm{Na}$ medida em que a antropologia e as pesquisas antropológicas têm sua história intimamente rel acionada a contextos col oniais e, como já foi de algum modo apontado no início deste texto, tendo sido postas em questão as relações entre antropólogos e agentes de governos colonialistas, gostaria, neste ponto, de me reter sobre o exemplo aqui exposto dos acontecimentos no acampamento indígena. Dados os el ementos que o conformaram, ele pode ser visto como um exemplo-limite do papel de mediação atribuído ao antropólogo, o que denota que há justamente um papel específico em questão. Esse exemplo permite exatamente - ou antes, suscita - uma reflexão sobre esse papel num nível mais amplo, e sobre sua relevância nos tempos atuais.

0 que estou considerando como esse papel de mediação não significa uma função política pretendida e assumida pelo próprio antropólogo, mas fundamental mente a tradução de interesses das partes em uma interação, sob explícita solicitação destas. A ssim, o quadro que pode se delinear é o de um mediador entre diferentes princípios culturais e de organização social, um mediador entre os grupos sociais e as mais distintas instituições públicas e privadas. 
0 que é de se observar é que não só diferentes princípios culturais demandam, no presente momento histórico, uma tradução entre e para as partes, mas sobretudo que essa diversidade encontra concretização através de uma estrutura hierárquica de poder, em que as decisões são tomadas, com um caráter marcadamente tutelar, externamente aos grupos social, política, cultural e economicamente sujeitados, pelas políticas dessas instituições públicas e privadas. Em vista dessa estrutura atualmente existente, o antropólogo é um mediador imprescindível e, no meu parecer, esse papel de mediação deve ser exercido buscando-se ao máximo conduzir à concretização dos direitos, e mais ainda, dos interesses desses grupos sujeitados. No processo, é de se prever (e fomentar) que o aprimoramento das organizações representativas desses mesmos grupos conduza a uma autonomia, a qual acabe por aportar transformações nesse papel.

\footnotetext{
Abstract: Following the critical analysis perspective on the anthropologist work fundaments, i. e., on the discipline conception, on the way they deal with their doject and on the methools they adopt do act so, in the current text I bring up for discussion the common-place, established throughout time, that has the anthropologists as being committed to the groups they work with. To do so, I use fundamentally the case of the Guarani people from Mato Grosso do Sul, where intense territory conflicts between the indigenous people and non-indigenous ones make the anthropologists to be more than simply researcher, a mediator in the many senses that the demands require, even under the risk of having their researches projects lost.
}

K ey-words: critical anthropology, anthropologist commitment, cultural mediation, Guarani indigenous people.

\section{Referências}

A SA D, Talal. Introduction; Two European images of non-European rule. In: _ (Ed.). Anthropology $\&$ the colonial encounter. New York: Humanities Press, 1973.

. From the history of colonial anthropology to the anthropology of western hegemony. In: TOCK IN G J R., G eorgeW. (Ed.). Colonial situations: essays on the contextualization of etnographic knowledge. The University of Wisconsin Press, 1991.
BOURDIEU, Pierre. 0 campo científico. In: ORTIZ, R. (Org.). Pierre Bourdieu. 2. ed. São Paulo: Ed. Ática, 1994.

As regras da arte: gênese e estrutura do campo literário. São Paulo: Companhia das Letras, 1996.

CHASE-SARDI, M.; BRUN, A.; ENCISO, M . A. Situación sociocultural, económica, jurídicopolítica actual de las comunidades indígenas en el Paraguay. A sunción: Cidsep, 1990.

ELIAS, N orbert. Engagement et distanciation: contribuitions à la sociologie de la connaissance. Paris: Fayard, 1993 [1983].

FABIAN, Johannes. Time and the other: how anthropology makes its objects. N ew Y ork: Columbia University Press, 1983.

. Time and the work of anthropology: critical essays 1971-1991. Harwood, 1991.

GLU CK M A N , M ax. A nálise de uma situação social na Zululândia moderna. In: FEL DM A N-BIA N CO, B ela (Org.). Antropologia das sociedades contemporâneas. São Paulo: Global, 1987 [1958].

GR ÜNBERG, G eorg. Indigenismo, movimenti pro indigeni e realtà indigene in A merica Latina. In: Ñandé Rekó: il nostro modo di essere. Roma: Cisu, 2000.

JAMES, Wendy. The anthropologist as reluctant imperialist. In: ASA D, Talal (ed.) Anthropology \& the Colonial Encounter. NY: Humanities Press. 1973.

KUPER, A dam. Anthropology and anthropologists: The B ritish School (1922-1972). L ondon: Allen Lane. 1973.

LIM A, A ntônio Carlos de S. U m grande cerco de paz: poder tutelar, indianidade e formação de estado no B rasil. Petrópolis: Vozes. 1995.

MELIÀ, Bartomeu. EI Guarani conquistado y reducido: ensayos de etnohistoria. v. 5. A sunción: Biblioteca Paraguaya de A ntropología, 1986.

M ELIÀ, Bartomeu; GRÜ NBERG, Friedl; GRÜN BER G, Georg. Los Paî-Tavyterã: etnografia guarani del Paraguai contemporaneo. Suplemento Antropológico de la Revista del Ateneo Paraguayo, v. XI, n. 1-2, 1976.

MURA, Fabio; THOM AZ DE A L M EIDA, Rubem. Relatório Antropológico de Revisão de Limites da T.I. P orto Lindo (J akarey). Brasília: Funai, 2002. [Mimeo.]

OLIV EIRA, J oão Pacheco de. 0 nosso governo: os Ticuna e o regime tutelar, São Paulo: M arco Zero; B rasília: M CT-CN Pq, 1988.

. U ma etnologia dos 'índios misturados'? Situação col onial, territorialização efluxos culturais. 
In: OLIVEIRA , J. P. de (Org.). A viagem da volta: etnicidade, política e reelaboração cultural no nordeste indígena. Rio de J aneiro: Contra Capa Livraria, 1999.

PAGDEN, A nthony. European encounter with the New World: from Renaissance to R omanticism. N ew Haven; L ondon: Yale U niversity Press, 1993.

. L ords of all the world: ideologies of Empire in Spain, B ritain and France (1550-1800). N ew Haven; London: Y ale U niversity Press, 1995.

PELS, Peter; SALEMINK, Oscar. L ocating the colonial subjects of anthropology. In: (Eds.).

Colonial subjects: essays on the practical history of anthropology. The University of M ichigan Press: A nn A rbor, 1999.

PPT/PG. Población y tierras indígenas en la región oriental de la República del Paraguay. A sunción, 1977.

ROJAS, A Ifonso V. A ntropología aplicada y indigenismo en A mérica L atina. América Indígena, $31(1), 1971$, p. 5-44.
SAID, Edward. Orientalismo: o Oriente como invenção do 0 cidente. São Paulo: Companhia das Letras, 1990.

STOCKING JR., George W. Colonial situations: essays on the contextualization of ethnographic knowledge. M adison: The U niversity of Wisconsin Press, 1988.

THOM AZ DE ALM EIDA, Rubem F. D o desenvolvimento comunitário à ação política: o projeto K aiowa-Ñ andeva como experiência antropológica. Rio de J anei ro: Contra Capa Livraria, 2001.

TODOROV, Tzvetan. A conquista da América: a questão do O utro. São Paulo: M artins Fontes, 1999 [1988].

WHITE, Hayden. Trópicos do discurso: ensaios sobre a crítica da cultura. São Paulo: Edusp, 1994.

ReCEBIDO EM AgOSTO de 2004 A provado em outubro de 2004 